\title{
CHANGES IN MOBILITY
}

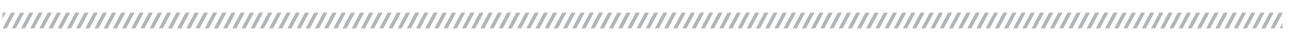

Dear Readers,

As is becoming evident, the transport network in our country - especially the urban areas - is increasingly becoming overloaded. Severe congestion in cities is also leading to increased levels of emissions. Recent data on Delhi suggests around a million vehicles got registered in the national capital over the last year alone, taking the city's overall vehicle population close to $10 \mathrm{mn}$ !

Additional transportation solutions are being put in place to ease out the chaos on roads, but there is a limit to how much can be done, considering there is always a want for physical space and government funds. There is a clear need to think differently, and introduce mobility solutions that are not just smart and integrated, but efficient and sustainable, adhering to the demands of environment compatibility. Any such mobility solutions must be able to react quickly to future demands; in fact, should be able to pre-empt many of those demands.

Countries and organisations have adopted a 'vision zero' approach to safety, but creating a transport environment that results in no fatality will still take time. But 'vision zero' could be a reality much earlier than we think.

Tesla, for instance, launched an update of its radar processing technology in September 2016 that was directly pushed over-the-air (OTA) to all its vehicles equipped with the first generation Autopilot hardware. The new radar is able to see ahead of the car in front of you and track two cars ahead on the road, something a driver potentially can't. In a recent accident in the Netherlands, a Tesla's Autopilot's Forward Collision Warning sensed that the vehicle in front was about to crash into an SUV that wasn't visible to the Tesla, and stopped.

There's phenomenal work happening worldwide to make transportation or mobility much smarter, safer and sustainable in the long run. In this first edition of 2017, we have focussed on and brought to you very interesting and insightful perspectives on aspects that are critical to future mobility networking, safety, connectivity, and autonomous vehicles. Hope you enjoy reading it as much as we have enjoyed brining this to you.

Here's wishing each one of you a delightful 2017!

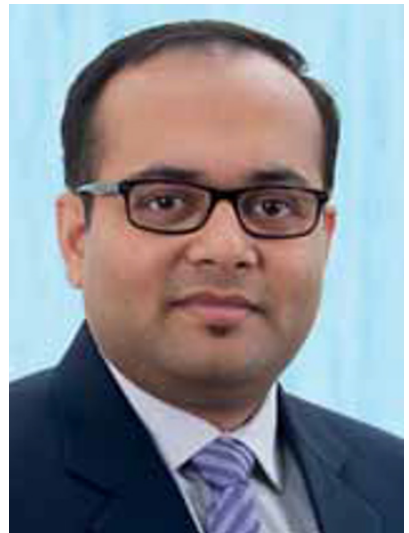

autotechreview.com

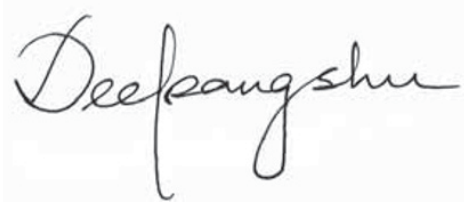

DEEPANGSHU DEV SARMAH

Editor-in-Chief

New Delhi, January 2017 